\title{
Multimodal treatment based on thyroidectomy improves survival in patients with metastatic anaplastic thyroid carcinoma: a SEER analysis from 1998 to 2015
}

\author{
Tao Song ${ }^{1}$, Long Chen ${ }^{1}$, Haibo Zhang ${ }^{1}$, Yanwei Lu ${ }^{1}$, Kun Yu ${ }^{2}$, Wenming Zhan ${ }^{1}$, Min Fang ${ }^{1}$ \\ ${ }^{1}$ Department of Radiation Oncology, Cancer Center of Zhejiang Provincial People's Hospital, Zhejiang Provincial People's Hospital, People's \\ Hospital of Hangzhou Medical College, Hangzhou, China; ${ }^{2}$ Department of Head \& Neck Surgery, Zhejiang Provincial People's Hospital, People's \\ Hospital of Hangzhou Medical College, Hangzhou, China \\ Contributions: (I) Conception and design: T Song, M Fang; (II) Administrative support: M Fang; (III) Provision of study materials or patients: T \\ Song, L Chen; (IV) Collection and assembly of data: T Song, L Chen, H Zhang; (V) Data analysis and interpretation: T Song, Y Lu, K Yu, W Zhan; \\ (VI) Manuscript writing: All authors; (VII) Final approval of manuscript: All authors. \\ Correspondence to: Dr. Min Fang. Department of Radiation Oncology, Zhejiang Provincial People's Hospital, People's Hospital of Hangzhou Medical \\ College, No. 158, Shangtang Road, Xiacheng District, Hangzhou 310000, China. Email: fanming@hmc.edu.cn.
}

Background: The aim of this retrospective study was to evaluate multimodal treatments consisting of surgery, radiotherapy (RT) and chemotherapy (CT) in metastatic anaplastic thyroid carcinoma (ATC) patients using the Surveillance, Epidemiology, and End Results (SEER) database.

Methods: Patients with a histopathologic diagnosis of ATC between 1998 and 2015 were included. The endpoint of this study was overall survival (OS). The prognostic significance in terms of OS was analyzed by univariate and multivariate analyses.

Results: A total of 433 metastatic ATC patients were identified. The median OS was two months, with a 1 -year OS rate of $6.9 \%$. In the multivariate analysis, the factors significantly correlated with OS were age $[<68$ vs. $\geq 68$ years old, $\mathrm{P}=0.032$, hazard ratio $(\mathrm{HR})=1.252$ ], tumor size $(<7 v s . \geq 7 \mathrm{~cm}, \mathrm{P}=0.004, \mathrm{HR}=1.418 ;<7 \mathrm{~cm}$ vs. unknown, $\mathrm{P}=0.005, \mathrm{HR}=1.424$ ), surgery at the primary site (none/unknown vs. less than thyroidectomy, $\mathrm{P}<0.001$, HR =0.623; none/unknown vs. thyroidectomy, $\mathrm{P}=0.001, \mathrm{HR}=0.616)$, use of $\mathrm{RT}(\mathrm{P}<0.001, \mathrm{HR}$ $=0.562)$ and use of CT $(\mathrm{P}<0.001, \mathrm{HR}=0.621)$. In the subgroup analysis, the combination of thyroidectomy, RT and CT demonstrated the best OS outcome when compared with other therapeutic modalities.

Conclusions: Surgery, RT and CT were all strong prognostic factors for improved OS in metastatic ATC patients. In addition, treatment approaches consisting of thyroidectomy were beneficial compared with nonsurgical treatment. However, given the limited benefit of only a few months in the clinic, we suggest that thyroidectomy in combination with RT and CT should be delivered in selected patients with caution for better management of metastatic ATC.

Keywords: Anaplastic thyroid carcinoma (ATC); SEER; thyroidectomy; radiotherapy; chemotherapy

Submitted May 13, 2020. Accepted for publication Sep 10, 2020.

doi: $10.21037 /$ gs-20-503

View this article at: http://dx.doi.org/10.21037/gs-20-503 


\section{Introduction}

Compared with differentiated thyroid cancers, anaplastic thyroid carcinoma (ATC) is a rare but deadly malignancy (1-3). Although it accounts for only $1-2 \%$ of all thyroid cancers, the disease-specific mortality approaches $100 \%(4,5)$. The median overall survival (OS) time for all stages is dismal at no better than a mere 5-6 months (6). Furthermore, due to its aggressive nature, nearly half of ATC patients would have distant metastasis (mATC) at initial diagnosis $(7,8)$.

Some retrospective analyses showed that surgical resection was considered as the main treatment approach for early-stage ATC patients who were willing to receive aggressive treatments $(6,9,10)$. However, for tumors that have extended from the capsule to adjacent structures or even distant sites (stage IVC), the benefit of surgery alone is limited (11), which leads to the integration of radiotherapy (RT) and chemotherapy (CT) as multimodality treatment for ATC patients (12-16). In a retrospective analysis from Memorial Sloan-Kettering Cancer Center from 1985 to 2010, 59 ATC patients who underwent surgery, RT and/ or CT had a 1-year disease-specific survival (DSS) of $42.4 \%$ compared to $6.0 \%$ for patients who underwent a single treatment $(\mathrm{P}<0.001)(17)$. Similarly, the results in another retrospective study from Germany also found that a multimodal treatment regimen was significantly associated with a survival benefit $(\mathrm{HR}=1.04, \mathrm{P}<0.0001)$ in stage IVC patients (18). However, due to the rarity of ATC, no well-designed, randomized trials have been conducted to evaluate the merits of multimodal therapy.

Presently, several changes have been made in the latest American Joint Committee on Cancer (AJCC) TNM $8^{\text {th }}$ edition for ATC, but the definition of stage IVC (mATC) did not change in the previous versions in the SEER (Surveillance, Epidemiology and End-Results) manual. To gain comprehensive insight into the treatment outcomes for mATC with a large cohort, we used the SEER registration program to explore the benefit of multimodal therapy, especially the use of thyroidectomy in mATC patients. We present the current study in accordance with the Strengthening the Reporting of Observational Studies in Epidemiology (STROBE) reporting checklist (available at http://dx.doi.org/10.21037/gs-20-503).

\section{Methods}

\section{Data source and patients}

The SEER database of the National Cancer Institute (NCI), provides the incidence and outcomes of histologically diagnosed malignancies from 17 registered medical institutions, which covers nearly $30 \%$ of the US population. We have gained permission to access the data for the purpose of research only (Reference number: 11656Nov2018). Because the data in the SEER database contain no personal identifiers and are publicly available after permission is obtained, the Institutional Review Board of Zhejiang Provincial People's Hospital exempted this study from review. The study was conducted in accordance with the Declaration of Helsinki (as revised in 2013). The International Statistical Classification of Diseases for Oncology, 3rd Edition (ICD-O-3), morphology code 8021, was used to identify ATC. The year 1998 was selected as the first year of this study given that detailed information on the item "surgery at the primary site" was collected from 1998.

Patients were chosen according to the following criteria: (I) histopathological diagnosis of ATC between 1998 and 2015; and (II) primary diagnosis of ATC. The main exclusion criteria were as follows: (I) patients who had more than one primary cancer; (II) patients with stage IVA-B and not specified disease (stage IVNOS) according to the SEER summary stage 1977 (1995-2000), SEER summary stage 2000 (2001-2003) and AJCC $6^{\text {th }}$ staging manual; and (III) patients with unknown follow-up data in the database. The flow chart of the patient selection is presented in Figure 1.

\section{Data analysis}

The following variables were collected from the SEER database: marital status, age at diagnosis, race, sex, surgery at the primary site, positive lymph nodes, use of RT, use of CT, cause of death (COD), SEER cause-specific death classification, SEER other cause of death classification, survival duration in months and vital status. For patients diagnosed before 2004, the variables of "tumor size" and "extent of disease (EOD)" were recorded as EOD 10-size (1988-2003) and EOD 10-extent (1988-2003) categories based on the SEER coding manual (https://seer.cancer. gov/archive/manuals/EOD10Dig.pub.pdf). For patients diagnosed between 2004 and 2015, the definitions of these two variables were recorded based on the "Collaborative stage (CS) tumor size (2004-2015)" and "CS extension (2004-2015)" criteria. As in other studies in the literature $(19,20)$, tumor extension was divided into four categories: (I) confined within the capsule, (II) extension into adjacent structures, (III) further extension or metastasis and (IV) 


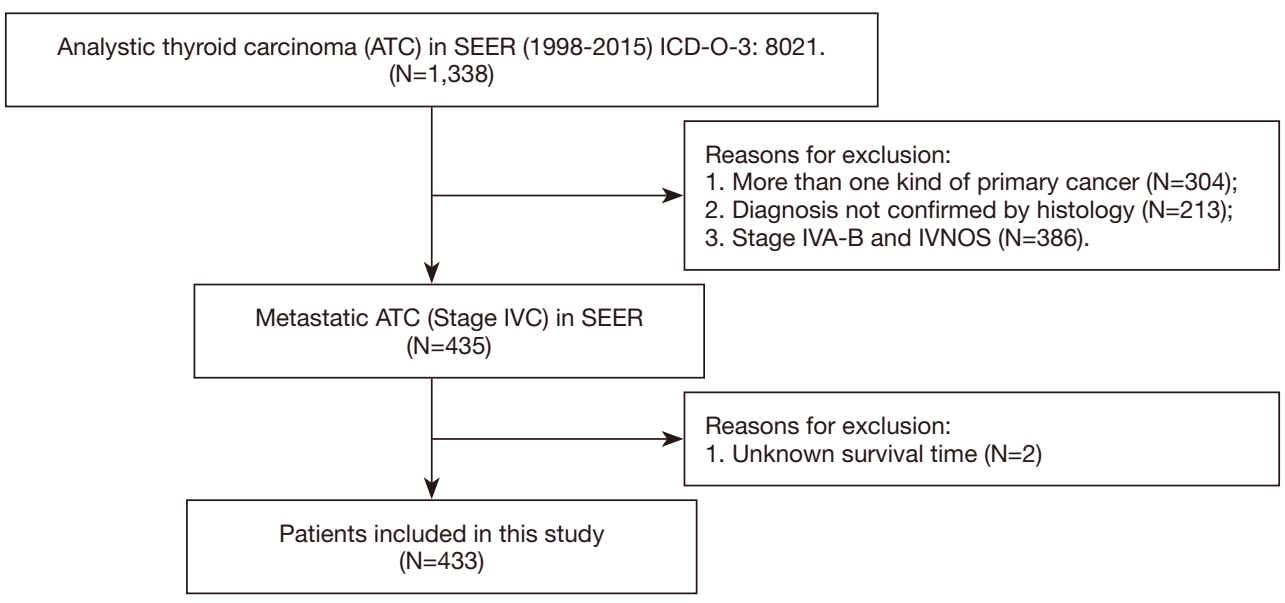

Figure 1 Flowchart summarizing patient enrollment.

unknown. To better illustrate the role of thyroidectomy in the management of mATC, surgery at the primary site was defined as (I) thyroidectomy; (II) less than thyroidectomy, which included isthmectomy only, less than lobectomy, lobectomy and/or isthmectomy, lobectomy only, lobectomy with isthmus, more than lobectomy and/or isthmectomy, removal of a lobe and partial removal of the contralateral lobe, subtotal or near total thyroidectomy and surgery, and NOS; and (III) none/unknown. The items cause-specific death classification and other cause of death classification indicated whether the person died of the cancer or of causes other than ATC. The primary outcome was OS. DSS was abandoned for further comparison because only 19 mATC patients (4.4\%) died of causes other than ATC in the whole cohort (detailed in the results section).

\section{Statistical analysis}

The OS and DSS were calculated by the Kaplan-Meier method and compared using the log-rank test. A univariate analysis was performed to identify the potential predictors for triple therapy (thyroidectomy combined with RT and CT) on one hand and to OS on the other hand. Multivariate analysis of the predictive factors for triple therapy was performed using binary logistic regression with calculation of the hazard ratios (HR) and 95\% confidence intervals (CI). Multivariate analyses of the predictive factors for OS were identified using a Cox regression model. A two-sided $\mathrm{P}$ value less than 0.05 was considered statistically significant. All statistical analyses were conducted using SEER ${ }^{\star}$ Stat 8.3.6 (NCI, Bethesda, MD, USA) and the IBM SPSS statistical software package, version 23.0 (SPSS, Armonk, New York, USA).

\section{Results}

\section{Demographic and clinicopathological characteristics}

After implementation of the inclusion and exclusion criteria, a total of 433 mATC patients diagnosed from 1998 to 2015 registered in the SEER database were included in the analysis (Table 1). The median age at diagnosis was 68 years old. A total of 332 patients were white (76.7\%), and more than half of the included patients were female (55.4\%). The median tumor size was $7.0 \mathrm{~cm}$. In total, 82 $(18.9 \%)$ mATC patients underwent thyroidectomy, while $60.1 \%$ patients did not receive surgery or the status was unknown (only three patients). A total of $23.6 \%$ of patients were diagnosed with positive lymph nodes. More than half of the patients received RT (56.1\%), and $40.2 \%$ of the patients were assigned to receive CT. In all, $32 \mathrm{mATC}$ patients received thyroidectomy combined with RT and CT. Multivariate analysis demonstrated that marital status (married vs. unmarried and others, $\mathrm{P}=0.039, \mathrm{HR}=2.708$ ), age at diagnosis $(<68 v s . \geq 68$ years old, $\mathrm{P}=0.012, \mathrm{HR}=3.143)$ and positive lymph nodes (none/negative $v s$. positive, $\mathrm{P}=0.001$, $\mathrm{HR}=0.265$; none/negative vs. unknown, $\mathrm{P}=0.142$, $\mathrm{HR}=0.282$ ) were significantly associated with triple therapy (Table S1).

\section{Prognostic factors for $O S$}

The median OS of the overall population was 2.0 months 
Table 1 Patient and disease characteristics

\begin{tabular}{|c|c|}
\hline Characteristic & Frequency (\%) \\
\hline \multicolumn{2}{|l|}{ Era of diagnosis } \\
\hline 1998-2003 & $123(28.4)$ \\
\hline 2004-2009 & $117(27.0)$ \\
\hline 2010-2015 & $193(44.6)$ \\
\hline \multicolumn{2}{|l|}{ Age (years) } \\
\hline Median (IQR) & $68(58.5-76)$ \\
\hline \multicolumn{2}{|l|}{ Marital status } \\
\hline Married & $253(58.4)$ \\
\hline Unmarried and others & $180(41.6)$ \\
\hline \multicolumn{2}{|l|}{ Race } \\
\hline White & $332(76.7)$ \\
\hline Non-white & $101(23.3)$ \\
\hline \multicolumn{2}{|l|}{ Sex } \\
\hline Female & $240(55.4)$ \\
\hline Male & $193(44.6)$ \\
\hline \multicolumn{2}{|l|}{ Tumor size $(\mathrm{cm})$} \\
\hline$<7$ & $152(35.1)$ \\
\hline$\geq 7$ & $146(33.7)$ \\
\hline Unknown & $135(31.2)$ \\
\hline \multicolumn{2}{|l|}{ Extent of disease } \\
\hline Confined within capsule & $34(7.8)$ \\
\hline
\end{tabular}

Table 1 (continued)

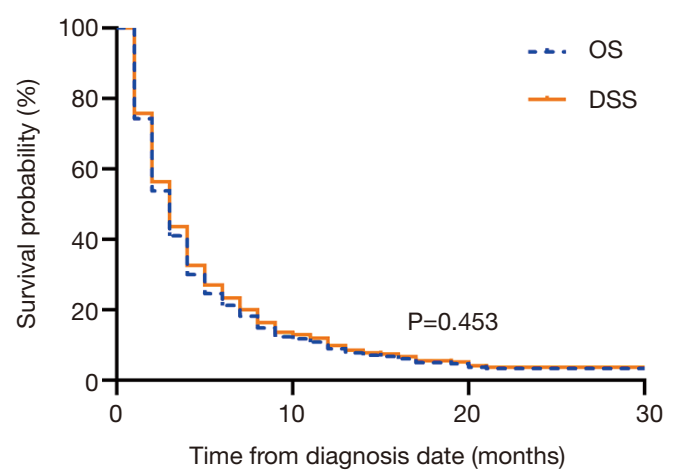

Figure 2 Comparison between OS and DSS. OS, overall survival; DSS, disease-specific survival.
Table 1 (continued)

\begin{tabular}{|c|c|}
\hline Characteristic & Frequency (\%) \\
\hline Extension to adjacent structures & $181(41.8)$ \\
\hline Further extension or metastasis & $180(41.6)$ \\
\hline Unknown & $38(8.8)$ \\
\hline \multicolumn{2}{|l|}{ Surgery at the primary site } \\
\hline None/Unknown & $260(60.1)$ \\
\hline Less than thyroidectomy & $91(21.0)$ \\
\hline Thyroidectomy & $82(18.9)$ \\
\hline \multicolumn{2}{|l|}{ Positive lymph nodes } \\
\hline None or negative & $312(72.1)$ \\
\hline Positive & $102(23.6)$ \\
\hline Unknown & $19(4.3)$ \\
\hline \multicolumn{2}{|l|}{ Radiation recode } \\
\hline No/Unknown & $190(43.9)$ \\
\hline Yes & $243(56.1)$ \\
\hline \multicolumn{2}{|l|}{ Delivery of radiotherapy } \\
\hline External beam radiation & $232(53.6)$ \\
\hline Others & $11(2.5)$ \\
\hline \multicolumn{2}{|l|}{ Chemotherapy recode } \\
\hline No/Unknown & $259(59.8)$ \\
\hline Yes & $174(40.2)$ \\
\hline
\end{tabular}

$I Q R$, interquartile range.
(95\% CI: $1.705-2.295)$. The 1 -year OS rate was $6.9 \%$ (95\% CI: $0.045-0.093)$. A total of 422 (97.5\%) mATC patients died during the follow-up period. Among them, $403(93.1 \%)$ patients died due to ATC, and the other 19 (4.4\%) mATC patients died of other causes. The median DSS was also 2.0 months (95\% CI: 1.686-2.314), with a 1 -year DSS rate of $7.7 \%$ (95\% CI: $0.052-0.102)$. The survival analysis indicated nearly overlapping curves for the two variables ( $\mathrm{P}=0.453$, Figure 2$)$. Based on this result, our further univariate and multivariate analyses were performed to determine correlations with OS.

Several covariates were significantly associated with OS (Table 2) according to the univariate log-rank test $(\mathrm{P}<0.05)$, 
Table 2 Univariate and multivariate analyses of OS

\begin{tabular}{|c|c|c|c|c|c|c|}
\hline \multirow{3}{*}{ Factor } & \multicolumn{6}{|c|}{ Overall survival (OS) } \\
\hline & \multicolumn{3}{|c|}{ Univariate } & \multicolumn{3}{|c|}{ Multivariate } \\
\hline & $P$ value & $\mathrm{HR}$ & $95 \% \mathrm{Cl}$ & $\mathrm{P}$ value & $\mathrm{HR}$ & $95 \% \mathrm{Cl}$ \\
\hline Marital status, married vs. unmarried and others & 0.068 & 1.199 & $0.986-1.456$ & - & & \\
\hline Age, $<68$ vs. $\geq 68$ & $<0.001$ & 1.436 & $1.183-1.742$ & 0.032 & 1.252 & $1.020-1.538$ \\
\hline Race, white vs. nonwhite & 0.035 & 1.277 & $1.018-1.602$ & 0.296 & 1.133 & $0.897-1.432$ \\
\hline Sex, female vs. male & 0.090 & 0.846 & $0.698-1.026$ & - & & \\
\hline Tumor size $(\mathrm{cm})$, reference: $<7$ & $<0.001$ & & & 0.004 & & \\
\hline$\geq 7$ & 0.002 & 1.449 & $1.148-1.829$ & 0.004 & 1.418 & $1.119-1.797$ \\
\hline Unknown & $<0.001$ & 1.666 & $1.312-2.117$ & 0.005 & 1.424 & $1.113-1.822$ \\
\hline Tumor extension, reference: confined within capsule & 0.258 & & & - & & \\
\hline Extension to adjacent structures & 0.685 & 0.926 & $0.638-1.344$ & & & \\
\hline Further extension or metastasis & 0.473 & 1.146 & $0.790-1.662$ & & & \\
\hline Unknown & 0.782 & 1.068 & $0.670-1.704$ & & & \\
\hline Surgery at the primary site, reference: None/Unknown & $<0.001$ & & & $<0.001$ & & \\
\hline Less than thyroidectomy & 0.002 & 0.682 & $0.534-0.873$ & $<0.001$ & 0.623 & $0.484-0.802$ \\
\hline Thyroidectomy & $<0.001$ & 0.561 & $0.432-0.727$ & 0.001 & 0.616 & $0.467-0.813$ \\
\hline Positive lymph nodes, reference: none or negative & 0.019 & & & 0.496 & & \\
\hline Positive & 0.006 & 0.720 & $0.571-0.909$ & 0.282 & 0.876 & $0.687-1.116$ \\
\hline Unknown & 0.861 & 1.042 & $0.655-1.658$ & 0.711 & 1.092 & $0.684-1.744$ \\
\hline Radiation recode, no/unknown vs. yes & $<0.001$ & 0.489 & $0.401-0.596$ & $<0.001$ & 0.562 & $0.456-0.691$ \\
\hline Chemotherapy recode, no/unknown vs. yes & $<0.001$ & 0.544 & $0.446-0.664$ & $<0.001$ & 0.621 & $0.502-0.767$ \\
\hline
\end{tabular}

$\mathrm{HR}$, hazard ratio; $\mathrm{Cl}$, confidence interval.

including age at diagnosis $(\mathrm{P}<0.001)$, race $(\mathrm{P}=0.035)$, tumor size $(\mathrm{P}<0.001)$, surgery at the primary site $(\mathrm{P}<0.001)$, positive lymph nodes $(\mathrm{P}=0.019)$, use of $\mathrm{RT}(\mathrm{P}<0.001)$ and use of $\mathrm{CT}(\mathrm{P}<0.001)$. In the multivariate analysis, the factors significantly associated with OS were age at diagnosis ( $<68$ vs. $\geq 68$ years old, $\mathrm{P}=0.032, \mathrm{HR}=1.252$ ), tumor size ( $<7$ vs. $\geq 7, \mathrm{P}=0.004, \mathrm{HR}=1.418 ;<7$ vs. unknown, $\mathrm{P}=0.005$, $\mathrm{HR}=1.424$ ), surgery at the primary site (none/unknown vs. less than thyroidectomy, $\mathrm{P}<0.001, \mathrm{HR}=0.623$; none/ unknown $v s$. thyroidectomy, $\mathrm{P}=0.001, \mathrm{HR}=0.616$ ), use of RT $(\mathrm{P}<0.001, \mathrm{HR}=0.562)$ and use of $\mathrm{CT}(\mathrm{P}<0.001$, HR $=0.621$, Figure 3$)$.

\section{Subgroup analysis of multimodal therapy}

We further conducted vertical and lateral comparative assessments for $82 \mathrm{mATC}$ patients who at least received thyroidectomy. In the vertical comparison, $32 \mathrm{mATC}$ patients received combination therapy with thyroidectomy, RT and CT. This treatment combination demonstrated the highest survival time compared with the other three treatment modalities. The median survival time for patients who received thyroidectomy, RT and CT was five months, and this was significantly prolonged the survival time of patients who received the other three treatment modalities $(\mathrm{P}<0.001$, Figure $4 A)$.

In the lateral comparison, 75 patients were recorded to have received RT and CT with no cancer-directed surgery. The median survival time for patients who received RT and CT was four months. Significant differences existed between patients who received thyroidectomy, RT and CT and those who received RT and CT without thyroidectomy 

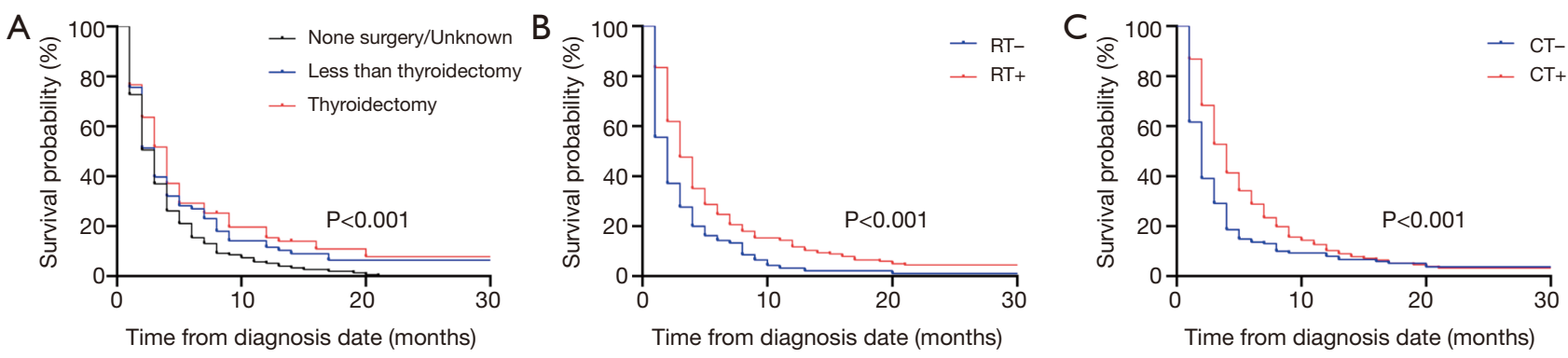

Figure 3 OS of mATC patients according to (A) surgery at the primary site; (B) use of RT; and (C) use of CT. OS, overall survival; mATC, metastatic anaplastic thyroid carcinoma; RT, radiotherapy; CT, chemotherapy.
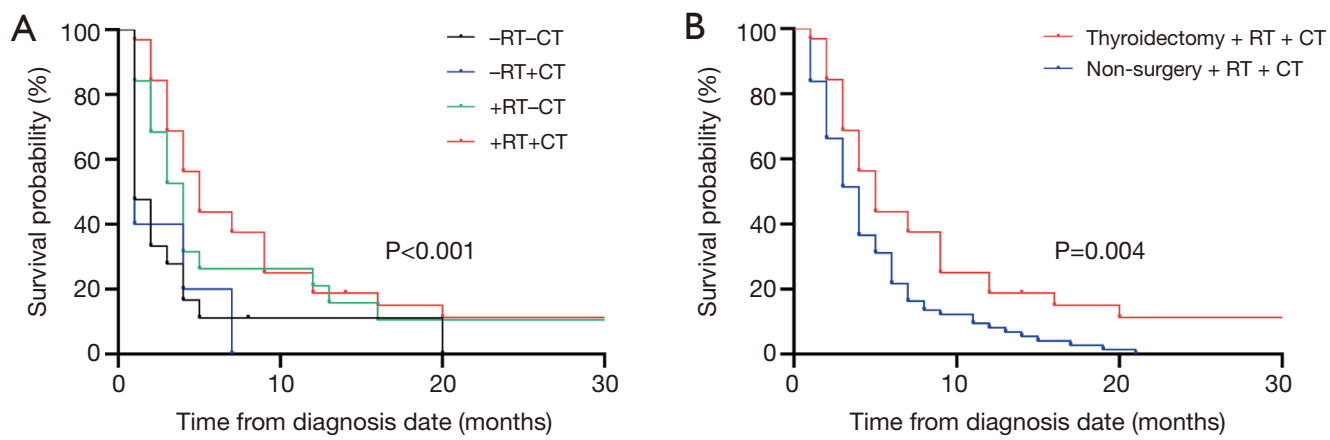

Figure 4 OS according to (A) different treatment approaches after thyroidectomy; and (B) thyroidectomy versus nonsurgical management for mATC. OS, overall survival; mATC, metastatic anaplastic thyroid carcinoma.

$(\mathrm{P}=0.004$, Figure $4 B)$.

\section{Discussion}

To the best of our knowledge, no specific study has been reported in the literature focusing on the treatment outcomes for stage IVC ATC. Thus, we could only evaluate the value of multidisciplinary treatment from studies with mixed stages IVA-B ATC. Previously, Swaak-Kragten and coworkers retrospectively reviewed the treatment outcomes of 75 ATC patients between 1972 and 2003 in the Netherlands. Among these patients, 30 (40\%) patients were diagnosed with stage IVC ATC. Although subsequent chemoradiation (CRT) therapy was associated with a significantly high incidence of acute toxicities, the survival benefit of multimodal therapy was remarkable, especially for patients who had undergone R0/R1 resection at the primary site (7). Recently, Tian et al. compared the efficiency of RT and CRT in ATC patients based on data from the National Cancer Database (NCDB). A total of 858 ATC patients between 2004 and 2013 were enrolled.
Among them, 330 (39.6\%) patients were diagnosed with metastatic disease. They found that CRT was associated with a significantly decreased risk of death $(\mathrm{HR}=0.66$, $\mathrm{P}<0.001)$. Furthermore, for patients who had undergone definitive surgery, CRT treatment demonstrated the greatest benefit when compared with RT alone (HR $=0.65$, $\mathrm{P}=0.009)$ (21). Another large-sample retrospective study with the use of the same SEER database data from 2004 to 2014 was reported in 2019 (20). In this report, over $40.0 \%$ of patients were diagnosed with distant metastasis. In contrast, the authors found that patients with very locally advanced disease or distant metastasis could not benefit from total/near-total thyroidectomy. The extremely fatal nature of ATC was the reason for this phenomenon in their conclusion. Taking into account the negative impact on quality of life, the 2012 American Thyroid Association did not uniformly recommend aggressive therapy for unselected mATC patients (6).

Currently, different opinions exist in the literature regarding the data extraction and analysis in a series of retrospective studies on the role of surgery. A profound 
analysis including 335 ATC patients registered in the NCDB found that $42.0 \%$ of patients were diagnosed with ATC intraoperatively. Additionally, 36.2\% of stage IVC patients achieved an $\mathrm{R} 0$ resection, while the R0 resection rates for stage IVA and IVB patients were $59.8 \%$ and $30.7 \%$, respectively. Combined with microscopically positive (R1) resection, stage IVC disease had a higher rate of surgical resection than stage IVB disease $(74.5 \%$ vs. $69.4 \%$ for stage IVC and IVB, respectively). Unsurprisingly, stage IVC patients with nonsurgical management had shorter median survival than stage IVC patients who underwent thyroidectomy $(\mathrm{P}=0.009)$. After adjusting for other factors, omission of surgery was still a significant factor associated with compromised survival for stage IVC patients (HR 1.35; $\mathrm{P}=0.033)$. Furthermore, no differences in survival were observed between different extents of resection (R0 vs. $\mathrm{R} 1$ vs. R2; $\mathrm{P}=0.548$ ) (22). In 2014, Brignardello et al. also reported their treatment results for ATC patients between 1999 and 2012. More than half of the enrolled patients (31/55) were diagnosed with stage IVC disease. An intention to obtain a macroscopically complete resection (R0 or $\mathrm{R} 1)$ or an R2 resection with minimal macroscopic residual tumor adherent to vital structures (pharynx, esophagus, larynx, or trachea) was defined as "maximal debulking" based on the surgeon's experience. Compared with operations that did not achieve this goal (partial debulking), maximal debulking was associated with significantly better survival (6.57 vs. 3.25 months for maximal debulking and partial debulking, respectively) without any significant difference between stage IVB and IVC ATC patients. Thus, the authors concluded that early maximal debulking, followed by multimodal therapy, could bring survival benefits for stage IVC patients and ameliorate poor quality of life by preventing the risk of suffocation (23). It should be noted that even with partial debulking, the 3.25-month median OS time was comparable with that in other retrospective studies for stage IVC patients $(24,25)$. An early SEER analysis conducted by Kebebew et al. also analyzed the prognostic factors and treatment outcomes in patients with ATC, and $43 \%$ of patients were diagnosed with distant metastasis among the 516 ATC patients. In a subgroup analysis, surgical resection combined with RT significantly decreased the cause-specific mortality rate in patients with regional and distant disease but not in patients with only intrathyroidal ATC (26). Another large-sample analysis conducted by Sugitani and his coworkers came from the ATC Research Consortium of Japan, which included 233 (41\%) stage IVC ATC patients from 1995 to 2008. In the multivariate analysis for metastatic disease, radical surgery was significantly associated with an improved survival rate compared with no resection or palliative resection (HR $=0.43,95 \%$ CI: 0.27-0.68; P=0.0003). Similarly, RT and $\mathrm{CT}$ were both strong prognostic factors associated with better survival, but slight difference existed between the two reports. We further demonstrated that advanced age at diagnosis and large tumor size were both correlated with worse OS in stage IVC ATC patients. Additionally, cause specific survival was set as the primary endpoint in Sugitani and his coworkers' study while OS was used in the current report (27). Furthermore, it must be pointed out that all these studies were analyzed with a retrospective design, and limited reports considering the impact of surgical resection on the quality of life for each individual are available.

Despite trimodality therapy, recent advances have suggested that the combination of a B-Raf kinase (BRAF) inhibitor and a mitogen-activated protein kinase (MAPK) kinase (MEK) inhibitor may have a profound and durable effect on patients with BRAF V600E-mutated ATC (28). Despite the different treatment therapies before enrollment, a phase II trial indicated that the response rate was $69 \%$ (95\% CI, 0.41-0.89), with a 1-year estimated OS rate of $80 \%$ (4). Additionally, immunotherapy in combination with targeted therapies has also shown promising results in some clinical cases. A retrospective study investigated the combination of salvage pembrolizumab with kinase inhibitors in twelve ATC patients. Partial response and stable disease was observed in $42 \%$ and $33 \%$ ATC patients, respectively. Median OS from the start of kinase inhibitor was 10.43 months and the median OS from the addition of pembrolizumab were 6.93 months with manageable adverse effects (29-31). Currently, a series of clinical trials assessing the efficacy of targeted therapies and immunotherapies are still ongoing, and we are awaiting their results $(32,33)$.

Many questions still remain unclear due to limitations of the SEER database. Firstly, it was impossible to document which patient would receive thyroidectomy or evaluate which extent of surgical resection was suitable for different patients. Secondly, detailed information about performance status, extent/number of metastatic sites, radiation dose, regimens for chemotherapy and subsequent treatment options including kinase inhibitors and immune therapies was also unavailable (34). In this regard, some bias might influence the final conclusion in this study.

In conclusion, we analyzed 433 mATC patients in the SEER database, and our results support the opinion that multimodality treatment can improve overall survival in 
ATC patients with metastatic disease. In addition, surgery with thyroidectomy is beneficial for mATC patients compared with nonsurgical treatment. However, although the statistical differences between different treatment modalities were significant, the true value of the multimodal approach, especially with surgical intervention, from the clinical point of view is still controversial. Thus, we recommend a surgical approach with careful pretreatment evaluation in combination with RT and CT for selected mATC patients in the future.

\section{Acknowledgments}

We thank the American Journal Experts (AJE) for their helps with translation and proofreading.

Funding: None.

\section{Footnote}

Reporting Checklist: The authors have completed the STROBE reporting checklist. Available at http://dx.doi. org/10.21037/gs-20-503

Conflicts of Interest: All authors have completed the ICMJE uniform disclosure form (available at http://dx.doi. org/10.21037/gs-20-503). The authors have no conflicts of interest to declare.

Ethical Statement: The authors are accountable for all aspects of the work in ensuring that questions related to the accuracy or integrity of any part of the work are appropriately investigated and resolved. Because the data in the SEER database contain no personal identifiers and are publicly available after permission is obtained, the Institutional Review Board of Zhejiang Provincial People's Hospital exempted this study from review. The study was conducted in accordance with the Declaration of Helsinki (as revised in 2013).

Open Access Statement: This is an Open Access article distributed in accordance with the Creative Commons Attribution-NonCommercial-NoDerivs 4.0 International License (CC BY-NC-ND 4.0), which permits the noncommercial replication and distribution of the article with the strict proviso that no changes or edits are made and the original work is properly cited (including links to both the formal publication through the relevant DOI and the license). See: https://creativecommons.org/licenses/by-nc-nd/4.0/.

\section{References}

1. Kitahara CM, Sosa JA. The changing incidence of thyroid cancer. Nat Rev Endocrinol 2016;12:646-53.

2. Perrier ND, Brierley JD, Tuttle RM. Differentiated and anaplastic thyroid carcinoma: Major changes in the American Joint Committee on Cancer eighth edition cancer staging manual. CA Cancer J Clin 2018;68:55-63.

3. Tiedje V, Stuschke M, Weber F, et al. Anaplastic thyroid carcinoma: review of treatment protocols. Endocr Relat Cancer 2018;25:R153-61.

4. Subbiah V, Kreitman RJ, Wainberg ZA, et al. Dabrafenib and Trametinib Treatment in Patients With Locally Advanced or Metastatic BRAF V600-Mutant Anaplastic Thyroid Cancer. J Clin Oncol 2018;36:7-13.

5. Chintakuntlawar AV, Foote RL, Kasperbauer JL, et al. Diagnosis and Management of Anaplastic Thyroid Cancer. Endocrinol Metab Clin North Am 2019;48:269-84.

6. Smallridge RC, Ain KB, Asa SL, et al. American Thyroid Association guidelines for management of patients with anaplastic thyroid cancer. Thyroid 2012;22:1104-39.

7. Swaak-Kragten AT, de Wilt JH, Schmitz PI, et al. Multimodality treatment for anaplastic thyroid carcinoma-treatment outcome in 75 patients. Radiother Oncol 2009;92:100-4.

8. De Crevoisier R, Baudin E, Bachelot A, et al. Combined treatment of anaplastic thyroid carcinoma with surgery, chemotherapy, and hyperfractionated accelerated external radiotherapy. Int J Radiat Oncol Biol Phys 2004;60:1137-43.

9. Akaishi J, Sugino K, Kitagawa W, et al. Prognostic factors and treatment outcomes of 100 cases of anaplastic thyroid carcinoma. Thyroid 2011;21:1183-9.

10. Dralle H, Musholt TJ, Schabram J, et al. German Association of Endocrine Surgeons practice guideline for the surgical management of malignant thyroid tumors. Langenbecks Arch Surg 2013;398:347-75.

11. Ranganath R, Shah MA, Shah AR. Anaplastic thyroid cancer. Curr Opin Endocrinol Diabetes Obes 2015;22:387-91.

12. Foote RL, Molina JR, Kasperbauer JL, et al. Enhanced survival in locoregionally confined anaplastic thyroid carcinoma: a single-institution experience using aggressive multimodal therapy. Thyroid 2011;21:25-30.

13. Käsmann L, Bolm L, Janssen S, et al. Prognostic Factors for Survival in Patients Treated with Multimodal Therapy for Anaplastic Thyroid Cancer. Anticancer Res 2016;36:4697-700. 
14. Pezzi TA, Mohamed ASR, Sheu T, et al. Radiation therapy dose is associated with improved survival for unresected anaplastic thyroid carcinoma: Outcomes from the National Cancer Data Base. Cancer 2017;123:1653-61.

15. So K, Smith RE, Davis SR. Radiotherapy in anaplastic thyroid carcinoma: An Australian experience. J Med Imaging Radiat Oncol 2017;61:279-87.

16. Prasongsook N, Kumar A, Chintakuntlawar AV, et al. Survival in Response to Multimodal Therapy in Anaplastic Thyroid Cancer. J Clin Endocrinol Metab 2017;102:4506-14.

17. Mohebati A, Dilorenzo M, Palmer F, et al. Anaplastic thyroid carcinoma: a 25-year single-institution experience. Ann Surg Oncol 2014;21:1665-70.

18. Wendler J, Kroiss M, Gast K, et al. Clinical presentation, treatment and outcome of anaplastic thyroid carcinoma: results of a multicenter study in Germany. Eur J Endocrinol 2016;175:521-9.

19. Chen J, Tward JD, Shrieve DC, et al. Surgery and radiotherapy improves survival in patients with anaplastic thyroid carcinoma: analysis of the surveillance, epidemiology, and end results 1983-2002. Am J Clin Oncol 2008;31:460-4.

20. Huang NS, Shi X, Lei BW, et al. An Update of the Appropriate Treatment Strategies in Anaplastic Thyroid Cancer: A Population-Based Study of 735 Patients. Int J Endocrinol 2019;2019:8428547.

21. Tian S, Switchenko JM, Fei T, et al. Survival advantage of chemoradiotherapy in anaplastic thyroid carcinoma: Propensity score matched analysis with multiple subgroups. Head Neck 2020;42:678-87.

22. Goffredo P, Thomas SM, Adam MA, et al. Impact of Timeliness of Resection and Thyroidectomy Margin Status on Survival for Patients with Anaplastic Thyroid Cancer: An Analysis of 335 Cases. Ann Surg Oncol 2015;22:4166-74.

23. Brignardello E, Palestini N, Felicetti F, et al. Early surgery

Cite this article as: Song T, Chen L, Zhang H, Lu Y, Yu K, Zhan W, Fang M. Multimodal treatment based on thyroidectomy improves survival in patients with metastatic anaplastic thyroid carcinoma: a SEER analysis from 1998 to 2015. Gland Surg 2020;9(5):1205-1213. doi: 10.21037/gs-20-503 and survival of patients with anaplastic thyroid carcinoma: analysis of a case series referred to a single institution between 1999 and 2012. Thyroid 2014;24:1600-6.

24. Are C, Shaha AR. Anaplastic thyroid carcinoma: biology, pathogenesis, prognostic factors, and treatment approaches. Ann Surg Oncol 2006;13:453-64.

25. Molinaro E, Romei C, Biagini A, et al. Anaplastic thyroid carcinoma: from clinicopathology to genetics and advanced therapies. Nat Rev Endocrinol 2017;13:644-60.

26. Kebebew E, Greenspan FS, Clark OH, et al. Anaplastic thyroid carcinoma. Treatment outcome and prognostic factors. Cancer 2005;103:1330-5.

27. Sugitani I, Miyauchi A, Sugino K, et al. Prognostic factors and treatment outcomes for anaplastic thyroid carcinoma: ATC Research Consortium of Japan cohort study of 677 patients. World J Surg 2012;36:1247-54.

28. Agrawal VR, Hreno J, Patil T, et al. New therapies for anaplastic thyroid cancer. Drugs Today (Barc) 2018;54:695-704.

29. Kollipara R, Schneider B, Radovich M, et al. Exceptional Response with Immunotherapy in a Patient with Anaplastic Thyroid Cancer. Oncologist 2017;22:1149-51.

30. Cabanillas ME, Ferrarotto R, Garden AS, et al. Neoadjuvant BRAF- and Immune-Directed Therapy for Anaplastic Thyroid Carcinoma. Thyroid 2018;28:945-51.

31. Iyer PC, Dadu R, Gule-Monroe M, et al. Salvage pembrolizumab added to kinase inhibitor therapy for the treatment of anaplastic thyroid carcinoma. J Immunother Cancer 2018;6:68.

32. Ljubas J, Ovesen T, Rusan M. A Systematic Review of Phase II Targeted Therapy Clinical Trials in Anaplastic Thyroid Cancer. Cancers (Basel) 2019;11:943.

33. Ferrari SM, Elia G, Ragusa F, et al. Novel treatments for anaplastic thyroid carcinoma. Gland Surg 2020;9:S28-S42.

34. Yu JB, Gross CP, Wilson LD, et al. NCI SEER publicuse data: applications and limitations in oncology research. Oncology (Williston Park) 2009;23:288-95. 


\section{Supplementary}

Table S1 Univariate and multivariate analyses of triple therapy

\begin{tabular}{|c|c|c|c|c|c|c|}
\hline \multirow{2}{*}{ Factor } & \multicolumn{6}{|c|}{ Triple therapy } \\
\hline & $P$ value & $\mathrm{HR}$ & $95 \% \mathrm{Cl}$ & $P$ value & $\mathrm{HR}$ & $95 \% \mathrm{Cl}$ \\
\hline Marital status, married vs. unmarried and others & 0.010 & 3.322 & $1.338-8.247$ & 0.039 & 2.708 & $1.050-6.985$ \\
\hline Age, $<68$ vs. $\geq 68$ & 0.001 & 4.128 & $1.746-9.763$ & 0.012 & 3.143 & $1.287-7.677$ \\
\hline Sex, female vs. male & 0.038 & 0.455 & $0.217-0.957$ & 0.326 & 0.669 & $0.300-1.493$ \\
\hline Tumor size, reference: $<7$ & 0.041 & & & 0.072 & & \\
\hline$\geq 7$ & 0.935 & 1.032 & $0.480-2.222$ & 0.979 & 1.011 & $0.442-2.314$ \\
\hline Unknown & 0.015 & 4.818 & $1.363-17.025$ & 0.028 & 4.280 & $1.171-15.640$ \\
\hline Further extension or metastasis & 0.939 & 1.062 & $0.222-5.079$ & & & \\
\hline Unknown & 0.502 & 2.312 & $0.200-26.708$ & & & \\
\hline Positive lymph nodes, reference: None or negative & $<0.001$ & & & 0.004 & & \\
\hline Positive & $<0.001$ & 0.217 & $0.102-0.465$ & 0.001 & 0.265 & $0.120-0.587$ \\
\hline Unknown & 0.213 & 0.370 & $0.077-1.771$ & 0.142 & 0.282 & $0.052-1.525$ \\
\hline
\end{tabular}

$\mathrm{HR}$, hazard ratio; $\mathrm{Cl}$, confidence interval. 